Int. J. Electrochem. Sci., 14 (2019) 4957 - 4973

\title{
Natural Kermes Dye as an Effective Additive for Electrochemical Deposition of Nickel from Watts-type Nickel Bath
}

\author{
Manal A. El Sayed ${ }^{l}$ and Magdy A.M. Ibrahim ${ }^{2, *}$ \\ ${ }^{1}$ Department of Physics, Faculty of Science and Arts, Qassim University, Bukairiayh, Qassim 51941, \\ KSA \\ ${ }^{2}$ Department of Chemistry, Faculty of Science, Ain Shams University, Abbassia, Cairo 11566, Egypt \\ "E-mail: imagdy1963@hotmail.com
}

doi: $10.20964 / 2019.06 .34$

Received: 28 January 2019 / Accepted: 23 March 2019 / Published: 10 May 2019

In this work, considerable improvements in the corrosion resistance as well as on the microhardness of the electrodeposited nickel from Watts-type nickel bath has been achieved by using Natural Kermes Dye (NKD) as an effective additive. The investigation was carried out to study the influence of different concentrations of NKD on the polarization behavior, anodic linear stripping voltammetry, cyclic voltammetry, cathodic current efficiency, current-time transients as well as on the microhardness. The microhardness was improved considerably, it changes from 130.4 to $225 \mathrm{~kg} \mathrm{f} \mathrm{mm}^{-2}$ in the presence 8.0 $x 10^{-6} \mathrm{M}$ NKD. Moreover, the corrosion resistance of Ni coating was enhanced about five times in the existence of $1.0 \times 10^{-5} \mathrm{M}$ NKD. On the other side, the inclusion of NKD to the plating electrolyte leads to a large move in the polarization as well as on the deposition potential to nobler potentials, pointing out a catalytic action of NKD on nickel deposition process. The kinetic information emphasized that the exchange current is significantly increased with enhancing NKD concentration while $\alpha_{c}$ remains nearly constant, supposes that the addition of NKD does not change the Ni deposition mechanism. The phases and morphology of the nickel coatings were checked in the absence and presence of NKD by XRD and SEM.

Keywords: Natural kermes dye; Ni electrodeposition; corrosion resistance; current efficiency; microhardness.

\section{$\underline{\text { FULL TEXT }}$}

(C) 2019 The Authors. Published by ESG (www.electrochemsci.org). This article is an open access article distributed under the terms and conditions of the Creative Commons Attribution license (http://creativecommons.org/licenses/by/4.0/). 